\title{
The Capital Asset Pricing Model and the Determination of Fair Underwriting Returns for the Property-Liability Insurance Industry
}

\author{
by Jorge L. Urrutia*
}

\section{Introduction}

Price regulation in the property-liability insurance industry in the United States has been characterized by the application of arbitrary rules of thumb to determine fair underwriting returns. The absence of definitive standards for regulating insurance prices has resulted in significant controversy among regulators, the insurance industry, and consumer groups. The debate has focused on the propriety of including investment income in the ratemaking formula. Even though several states have adopted pricing formulas that take into account this important source of income for the insurance industry, there is no general agreement about the precise form for incorporating it in the rating formula. The insurance ratemaking problem has also been a major concern of academicians. In this respect, several theoretical models attempting to solve the insurance pricing problem by considering both underwriting profit and investment return have been developed. The implementation of those models has also followed different empirical approaches. Nevertheless, a model developed by Fairley [10] has concentrated the attention of academicians, insurance people, and regulatory authorities, mainly because it has been the basis of the determination of insurance rates by the Massachusetts Commissioner of Insurance.

Fairley's model is based on the Capital Asset Pricing Model (CAPM). The CAPM was built under several simplifying assumptions ${ }^{1}$ however, the model has performed fairly well in

* Assistant Professor, Department of Finance, Graduate School of Business, Loyola University of Chicago, USA.

'The assumptions of the traditional CAPM are the following:

- Investors are risk averse who maximize the expected utility of their end of the period wealth.

- Investors are price takers and have homogeneous expectations about asset returns, which have a joint normal distribution.

- There exists a risk-free asset such that investors may borrow or lend unlimited amounts at the risk-free rate.

- The quantities of assets are fixed. All assets are marketable and perfectly divisible.

- Asset markets are frictionless and information is costless and simultaneously available to all investors.

- There are no market imperfections such as taxes, regulations, or restrictions on short sellings. 
empirical tests and applications to real-world problems. ${ }^{2}$ While several criticisms of the Fairley model are related to the assumptions underlying the CAPM, the most relevant criticisms have to do with Fairley's specific assumptions. ${ }^{3}$ In effect, Fairley assumes that the systematic risk of insurer's liabilities is constant for all the insurance lines. This assumption, as Fairley himself points out, is not quite evident and should be relaxed. Fairley also adopts a very simplified treatment of corporate taxation by assuming the same tax rate for underwriting and investment activities. Finally, another important shortcoming in the Fairley model is the lack of consideration of the risk of insolvency of the insurer.

The proposed model drops the assumption of a constant liabilities beta for all lines. The systematic underwriting risks for individual insurance lines are computed by applying a risk proportional method. Under this method, underwriting profit of the insurance portfolio is distributed among the different insurance lines according to their contribution to the risk of the insurance portfolio. The suggested model also recognizes different tax rates for underwriting profit and investment income. Finally, the proposed model incorporates a statistically determined capital, which takes into account the probability of bankruptcy of the insurance company.

The main conclusions of the empirical tests can be summarized as follows: The underwriting returns given by the proposed model are negative. This means insurance companies make the money mainly in their investment activities. The proposed model represents the data better than the Fairley model. The predictability of the proposed model is increased when the probability of bankruptcy of the insurer and different corporate tax rates for investment income and underwriting profit are incorporated into the model. Sensitivity analysis reveals that the temporal and sectional variations of the underwriting beta have no statistically significant effect in the underwriting returns.

\section{The proposed model}

The derivation of the proposed model is presented in this section. Underwriting return formulas based on the CAPM and portfolio theory are derived for three cases: the before-tax, after-tax and tax-differential cases.

\subsection{The before-tax case}

Insurance companies perform two kinds of activities: underwriting and investment activities. Insurer sell insurance policies through their underwriting operations and invest the

\footnotetext{
${ }^{2}$ Empirical tests of the CAPM are presented in Black, Jensen and Scholes [4], Fama and MacBeth [11], and elsewhere.

${ }^{3}$ See, for instance, Myers and Cohn [22] and Callaghan and Derrig [6].
} 
proceeds in the stock markets. ${ }^{4}$ Therefore, an insurance company can be seen as having two kinds of portfolios: the insurance portfolio and the investment portfolio. The insurance portfolio is composed of all insurance lines in which the insurer writes policies. The investment portfolio is composed by all invested assets. In this context, the expected return on equity for a multi-line insurance firm can be established through the portfolio approach, already utilized by Biger and Kahane [3] and other authors, ${ }^{5}$ as follows:

$$
\bar{R}_{k}=\sum_{j=1}^{m} d_{j} \cdot \bar{\mu}_{j}+\sum_{i=1}^{n} c_{i} \cdot \bar{R}_{i}
$$

where:

$$
\begin{aligned}
& \bar{R}_{k}=\text { expected rate of return on equity, } \\
& \bar{R}_{i}=\text { expected rate of return on the ith investment, for } i=1 \text { to } n \\
& \bar{\mu}_{j}=\text { expected underwriting return on the } j \text { th insurance line for } j=1 \text { to } m, \\
& c_{i}=\frac{A_{i}}{K}=\text { investment in the } i \text { th-asset-to-equity ratio, } \\
& d_{j}=\frac{P_{j}}{K}=\text { premiums earned in the } j \text { th insurance line-to-equity ratio, } \\
& A_{i}=\text { investment in the } i \text { th asset, } \\
& P_{j}=\text { premiums earned in the } j \text { th insurance line, } \\
& K=\text { insurance company equity. }
\end{aligned}
$$

In the above formula, the first term in the right-hand side represents the underwriting profit per unit of equity earned by the firm in the insurance portfolio. The second term corresponds to the return per unit of equity earned by the firm in its investment portfolio.

On the other hand, a target return or competitive rate of return on equity for a multi-line insurer is given by the CAPM: ${ }^{6}$

\footnotetext{
${ }^{4}$ Insurance companies collect premiums in advance and pay losses over the time. Investment income arises because of the lag between collection of premiums and payment of losses. In fact, insurers invest the loss reserve, unearned premium reserve and the capital. However, the capital is an unimportant source of investment relative to the reserves.

${ }^{5}$ See for example Cooper [7], Cummins and Nye [9], Ferrari [12], Haugen and Kroncke [13], Kahane and Nye [17] and Krouse [19].

${ }^{6}$ Formula (2) assumes that $R_{m}$ and $R_{f}$ are after-tax returns.
} 
(2)

$$
\bar{R}_{k}^{c}=R_{f}+\beta_{k}\left(\bar{R}_{m}-R_{f}\right)
$$

where:

$\bar{R}_{k}^{c}=$ expected competitive rate of return on equity,

$R_{f}=$ rate of return on the risk-free security,

$\bar{R}_{m}=$ expected rate of return on the market portfolio,

$\beta_{k}=$ total systematic risk of the insurer's equity or overall beta coefficient.

For a single asset, the expected competitive rate of return is also given by the CAPM. Therefore, by summing over $c_{i}$ and replacing in (l) we get:

$$
\bar{R}_{k}=R_{f} \sum_{i=1}^{n} c_{i}+\left(\bar{R}_{m}-R_{f}\right) \sum_{i=1}^{n} c_{i} \cdot \beta_{i}+\sum_{j=1}^{m} d_{j} \cdot \bar{\mu}_{j} .
$$

From the linearity property of beta, we also have that the beta of insurer's equity is a weighted average of the betas of the investment and insurance portfolios. By using this property, equation (2) becomes

$$
\bar{R}_{k}^{c}=R_{f}+\left(\sum_{i=1}^{n} c_{i} \cdot \beta_{i}+\sum_{j=1}^{m} d_{j} \cdot \bar{\mu}_{j}\right)\left(\bar{R}_{m}-R_{f}\right) .
$$

Let us now define the following:

$$
\begin{aligned}
& b_{j}=\frac{P_{j}}{T P}=\text { the premiums earned in the } j \text { th insurance line, } P_{j}, \text { to total premiums } \\
& \text { earned, } T P, \text { ratio. } \\
& T A=K+\sum_{j=1}^{m} k_{j} \cdot P_{j}
\end{aligned}
$$

or : $\quad$ Total Assets $=$ Capital + Liabilities

$k_{j}$ is the amount of investable funds generated by each dollar of premium earned in the $j$ th insurance line. Therefore, the term $\sum_{j=1}^{m} k_{j} \cdot P_{j}$ represents the reserves or liabilities of the insurance firm. By using the above definitions and by equating (3) and (4), we get the following formula for the underwriting return per unit of premium earned of the insurance portfolio.

$$
\sum_{j=1}^{m} b_{j} \cdot \bar{\mu}_{j}=-R_{f} \sum_{j=1}^{m} b_{j} \cdot k_{j}+\left(\bar{R}_{m}-R_{f}\right) \sum_{j=1}^{m} b_{j} \cdot \beta_{j}
$$

Let us now recall the following identities:

$$
\begin{aligned}
& \bar{\mu}=\sum_{j=1}^{m} b_{j} \cdot \bar{\mu}_{j}=\begin{array}{l}
\text { expected underwriting return per unit of premium earned of the } \\
\text { insurance portfolio, }
\end{array} \\
& \beta_{\mu}=\sum_{j=1}^{m} b_{j} \cdot \beta_{j}=\begin{array}{l}
\text { beta coefficient or systematic underwriting risk of the insurance } \\
\text { portfolio, }
\end{array}
\end{aligned}
$$




$$
k_{\mu}=\sum_{j=1}^{m} b_{j} \cdot k_{j}=\begin{aligned}
& \text { average amount of investable funds generated by one dollar of pre- } \\
& \text { mium earned. }
\end{aligned}
$$

By replacing the above definitions in equation (5), we get:

$$
\bar{\mu}=-k_{\mu} \cdot R_{f}+\beta_{\mu}\left(\bar{R}_{m}-R_{f}\right) .
$$

In equation (6), the first term in the right-hand side represents an implicit interest rate paid to the policyholders for the use of their cash flows, and the second term corresponds to the risk premium associated with the underwriting risk. ${ }^{7}$ The formula is similar to the Fairley model.

\subsection{The after-tax case}

Let us now introduce a single corporate tax rate, $t$, for investment income and underwriting profit. Under this situation, the after-tax expected return on equity is derived by multiplying both sides of equation (3) by (1-t). On the other hand, the after-tax target return on equity is obtained by replacing an after-tax beta of equity in equation (4). By equating the after-tax versions of the expected return and the target return and by proceeding in a similar fashion to the before-tax case, we arrive at the following formula for the after-tax underwriting return of the insurance portfolio:

$$
\bar{\mu}^{\prime}=-k_{\mu} \cdot R_{f}+\beta_{\mu}\left(\bar{R}_{m}-R_{f}\right)+R_{f}\left(\frac{K}{T P}\right)\left(\frac{t}{1-t}\right) .
$$

In the above formula, the third term in the right-hand side represents the effect of taxation; as expected, the insurance firm requires a higher underwriting return when taxes are brought into the model. Equation (7) is equivalent to the after-tax Fairley model, but in our formula the insurer's equity has a different interpretation and serves a different purpose, as will be shown later in this paper.

The Fairley model assumes the same tax rate for underwriting profit and investment income. However, a more realistic treatment of the taxation problem should assume different tax rates for these two sources of revenues of an insurance company. The consideration of different tax rates for underwriting profit and investment income is another important deviation of the proposed model from the Fairley model. Let us define:

$$
\begin{aligned}
& t_{\mu}=\text { corporate tax rate for underwriting profit, } \\
& t_{i}=\text { corporate tax rate for investment income. }
\end{aligned}
$$

\footnotetext{
${ }^{7}$ Insurance companies are financial intermediaries: they collect premiums in advance and invest the proceeds in the stock market. However, unlike other financial intermediaries, insurers do not pay an explicit interest rate for the use of the money of the policyholders. The negative term in equation (6) represents precisely an implicit interest rate paid to the insurance consumers for the loan of their cash flows.
} 
The after-tax expected return on equity can be easily obtained from equation (3) by multiplying the investment income by $\left(1-t_{i}\right)$ and the underwriting profit by $\left(1-t_{u}\right)$. On the other hand, the after-tax competitive rate of return on equity is derived from equation (4) by replacing an after-tax systematic risk of equity.

By equating the differential-tax expressions of the expected and the target returns, we come up to the following formula for the after-tax underwriting profit per dollar of premium earned.

$$
\bar{\mu}^{T}=-k_{\mu} \cdot R_{f}\left(\frac{1-t_{i}}{1-t_{\mu}}\right)+\beta_{\mu}\left(\bar{R}_{m}-R_{f}\right)+R_{f}\left(\frac{K}{T P}\right)\left(\frac{t_{i}}{1-t_{\mu}}\right)
$$

\section{Statistically determined capital}

The formulas already derived in Section 2 contain the equity of the insurer as an element in the determination of the underwriting returns on the insurance portfolio. In this paper, the theoretical interpretation of this capital represents an important departure from the Fairley model.

Hofflander and Duvall [15] consider that the equity to be used in the computation of the rate of return of an insurance company should be what they call the statistically determined capital and not just the book value or market value capital. The most relevant characteristic of the statistically determined capital is that is takes into account the probability of insolvency of the insurer. However, the aforementioned authors ignore the investment income and its risk. In effect, they assume the investment portfolio is riskless. Hence, in their formulas the statistically determined capital is a function only of the inter-period fluctuations in the losses and expenses of the various lines composing the insurance portfolio.

The assumption of a risk-free investment portfolio is relaxed in this paper. Consequently, the capital required by the insurance company must account for both the fluctuations in losses and expenses of the lines in the insurance portfolio and in prices or returns of the assets in the investment portfolio. For the derivation of the formulas for the statistically determined capital, we will proceed as follows:

Let us define the average combined ratio as:

$$
\overline{C R}_{\mu}=\sum_{j=1}^{m} b_{j} \cdot \overline{C R}_{j}
$$

where

$$
\begin{aligned}
b_{j}= & \text { ratio of premiums earned in the } j \text { th insurance line to the total premiums earned, } \\
& \text { as before, } \\
\overline{C R}_{\mu}= & \text { expected combined losses and expenses to premiums earned ratio for the insur- } \\
& \text { ance portfolio, } \\
\overline{C R}_{j}= & \begin{array}{l}
\text { expected combined losses and expenses to premiums earned ratio for the } j \text { th } \\
\text { insurance line. }
\end{array}
\end{aligned}
$$


Let us also define:

$$
\bar{R}_{a}=\sum_{i=1}^{n} a_{i} \cdot \bar{R}_{i}
$$

where

$\bar{R}_{a}=$ the expected return on the investment portfolio,

$R_{i}=$ expected return on the $i$ th asset, as before,

$a_{i}=\frac{A_{i}}{T A}=$ investment in the $i$ th asset, $A_{i}$, to total investment in assets, $T A$, ratio.

Given the above definition, the statistically determined capital, $K$, can be computed from the following formula:

$$
K_{s}=T P\left(\overline{C R}_{\mu}+t_{\alpha} \cdot \sigma_{p}\right)-T P\left(1+\frac{T A}{T P} \bar{R}_{a}\right),
$$

where

$$
\begin{aligned}
\sigma_{p} & =\text { standard deviation of the insurer's total profit per unit of premium earned, } \\
t_{\alpha} & =\text { the statistic } t \text { value corresponding to a specified confidence level, } 1-\alpha,
\end{aligned}
$$

and other terms as before.

In formula (11), the first term in the right-hand side represents the total expected losses plus total expenses incremented by a factor that accounts for the variation in the insurance company costs due to both the fluctuations in the insurance and investment portfolios. The second term in the right-hand side corresponds to the total revenues obtained by the insurer from its underwriting and investment activities.

The above formula states that losses and expenses that are not covered by underwriting profit and investment income must be absorbed by the equity to avoid bankruptcy. The role of the statistically determined capital is clear: a cushion for absorbing losses and expenses in excess of the total revenues of the insurer. The amount of capital is a very important parameter, and it is closely observed by regulators. In fact, the solvency of the insurance firm is the major concern of the regulatory authorities.

The standard deviation of the total profit per dollar of premium is just the square root of the variance of the total profits. That is, the square root of the following expression:

$$
\operatorname{var}(\tilde{P})=\operatorname{var}\left(\tilde{\mathrm{C}} \mathrm{R}_{\mu}\right)+\left(\frac{T A}{T P}\right)^{2} \operatorname{var}\left(\tilde{R}_{a}\right)-2\left(\frac{T A}{T P}\right) \operatorname{cov}\left(\tilde{R}_{a}, \tilde{C} R_{\mu}\right)
$$

$$
\begin{aligned}
& \operatorname{var}(\tilde{P}) \quad=\text { variance of total profits, } \\
& \operatorname{var}\left(\tilde{C} R_{\mu}\right) \quad=\text { variance of the insurance portfolio, } \\
& \operatorname{var}\left(\tilde{R_{a}}\right) \quad=\text { variance of the investment portfolio, }
\end{aligned}
$$


$\operatorname{cov}\left(\tilde{R_{a}}, \tilde{C} R_{\mu}\right)=$ covariance between investment and insurance portfolio,

and the other terms as before.

\section{The determination of underwriting returns by line of insurance}

The main purpose of this paper is the determination of underwriting returns by line of insurance. The computation of underwriting returns by individual lines is a complex matter because the systematic underwriting risks or underwriting betas for insurance lines are not observable. There are no underwriting market betas simply because particular insurance lines are not traded in the market. In this paper, the underwriting returns by lines are obtained by multiplying the overall underwriting return of the insurance portfolio by factors proportional to the risk associated with the individual lines. The methodology used is the following:

First of all, the systematic risk of the insurance portfolio is computed from the following after-tax version $\beta_{\mu}$ :

$$
\beta_{\mu}=\frac{K}{(1-t) T P} \beta_{K}-\left(k_{\mu}+\frac{K}{T P}\right) \beta_{a} .
$$

Following, the expected underwriting profit of the insurance portfolio per unit of premium earned for the after-tax and tax-differential cases are computed by replacing the different parameters in formulas (7) and (8), respectively.

Once the expected underwriting return on the insurance portfolio is known, the underwriting returns for individual insurance lines a re determined by following a methodology proposed by Cooper [7]. The idea underlying Cooper's approach is that each insurance line contributes to the total rate of return on underwriting activities in the same proportion that it contributes to the total underwriting risk of the insurance portfolio. Let us define:

$$
V_{j}=\frac{C_{j}}{\operatorname{var}\left(\tilde{C} R_{\mu}\right)}=\frac{\sum_{\ell=1}^{m} b_{j} \cdot b_{\ell} \cdot \sigma_{C R_{j}, C R_{\ell}}}{\sum_{j=1}^{m} \sum_{\ell=1}^{m} b_{j} \cdot b_{\ell} \cdot \sigma_{C R_{j}, C R_{\ell}}}
$$

where:

$V_{j}=$ relative contribution, or risk coefficient, of the $j$ th insurance line to the total underwriting risk of the insurance portfolio.

Clearly, $\sum_{j=1}^{m} V_{j}=1$.)

$C_{j}=$ covariance of the $j$ th insurance line with all the lines in the insurance portfolio, $\operatorname{var}\left(\tilde{C} R_{\mu}\right)=$ variance of the insurance portfolio, as before,

$\sigma_{C R_{j}, C R_{l}}=$ covariance between the $j$ th and $\ell$ th insurance lines, 
$b_{j}, b_{\S}=$ weights given by the ratio of the premiums earned on a particular insurance line to the total premium earned by the insurance portfolio.

After computing estimate for the $V_{j}$ 's, we calculate the expected underwriting return for the $j$ th insurance line as:

$$
\bar{\mu}_{j}=V_{j} \cdot \bar{\mu}(\cdot)
$$

where $\bar{\mu}(\cdot)$ represents the underwriting return for the insurance portfolio.

Our procedure presents an important difference with the approach followed by Fairley [10]. In effect, Fairley obtains an all-lines estimate for the liabilities beta. Following, he estimates the underwriting beta for the $j$ th insurance line by means of the following expression:

$$
\beta_{p, j}=-k_{j} \cdot \beta_{\iota}
$$

where:

$\beta_{p, j}=$ underwriting beta for the $j$ th insurance line,

$\beta_{L}=$ beta of insurer's liabilities,

$k_{j}=$ investable funds generated by the cash flow per dollar of premium earned in the $j$ th insurance line; as before, $k_{j}$ can be obtained by dividing the reserves by the premiums earned in the $j$ th insurance line.

Equation (16) implies that $\beta_{L}$ is the same for all insurance lines. In other words, all the reserves have the same level of risk. This is a strong assumption. In addition, $k_{j}$ represents a rough estimate of the risk associated with the $j$ th insurance line. The assumption underlying formula (15), on the other hand, is based on the portfolio theory and on the basic principle that riskier (less risky) assets should earn higher (lower) returns.

\section{Data specification and empirical tests}

The effectiveness of the alleged improvements of the proposed model over the Fairley model and other previous models, such as the Hill model [14], has been evaluated by conducting empirical tests. The required data, the different tests conducted, and the results obtained are described and presented in this section.

\subsection{Data description}

Most of the data utilized in this research correspond to the time period 1978-1982. However, parameter values for betas and corporate taxes correspond to the time period 19751979, and they have been taken from a report prepared by Callaghan and Derrig for the Insurance Bureau of Massachusetts [6]. The risk-free rate of return, $R_{f}$, is the one-year U.S. Treasury bond yield taken from the Wall Street Journal. The risk premium, $\bar{R}_{m}-R_{f}$, is taken from Ibbotson and Sinquefield [16]. 
Parameter values for the combined ratios, premiums written, premiums earned, reserves and policyholders surplus are taken from the Best Company. Statistics about the dollar amount of invested assets and their rates of returns are taken from the financial statements submitted by the companies to the Texas States Board of Insurance. These data are used to compute the standard deviation of insurers' total profit and the statistically determined capital.

Data limitations impose some constraint in the empirical tests. Therefore, the numerical results should not be taken as definitive. It is thought that a better set of data, i.e., quarterly or monthly, may greatly improve the reliability and predictibility of the proposed model.

\subsection{Results of the empirical tests}

Four different versions of the proposed model are used in the empirical tests. The first version is the simple case of market value capital and single-tax rate; the second version introduces different taxation for investment income and underwriting profit; the other two versions incorporate the probability of bankruptcy by means of the statistically determined capital for the single-tax and differential-tax cases, respectively.

Table l gives the risk coefficient for each insurance line, the investable funds generated by dollar of premium earned and the underwriting betas of the Fairley model. Table 2 presents the underwriting returns by line of insurance given by the different versions of the proposed model.$^{8}$ For purposes of comparison, the underwriting returns of the Fairley model and the historical and traditional target underwriting returns are also shown in Table 3.

InTable 2, we can see that the underwriting returns given by the proposed model are negative for all the insurance lines considered in the sample. These results were expected and agree with those reported earlier by Fairley. Negative underwriting returns imply insurance companies make their profits mainly in their investment operations. By comparing Tables 2 and 3, we can conclude that the underwriting returns by line of insurance given by Fairley's model are highly negative and several points below the historical returns. On the other hand, the underwriting returns given by the proposed model are very close to the actual returns. In fact, the weighted average underwriting profit margins given by the proposed model deviate from the historical returns no more than 1.4 points, while the underwriting returns of the Fairley model are about 3.2 points below the historical returns. Clearly, the underwriting returns given by the different versions of the proposed model are also much closer to the historical returns than the traditional target returns.

By taking the actual or historical returns as a reference framework, we can also conclude that the introduction of different tax rates for underwriting profits and investment income improves the potential predictability of the proposed model. In effect, we can see from the

${ }^{8}$ The statistically determined capital yields small values for the premium-to-capital ratio. These low values imply that insurance companies carry excess capital. This result agree with Cooper [7], who found that insurance firms were highly over capitalized. This is not surprising because, as it was already noted, the regulation of the insurance industry puts strong emphasis on the solvency of the insurers. In the computation of the statistically determined capital, an $\alpha$ of .05 is used. Other levels of $\alpha$ alter the figures but not the direction of the results obtained in this paper. 
Table 1: Risk coefficients, investable funds, and underwriting betas by line of insurance

\begin{tabular}{lccc}
\hline Line of Insurance & $\begin{array}{c}\text { Risk } \\
\text { Coefficient } \\
V_{j}\end{array}$ & $\begin{array}{c}\text { Investable } \\
\text { Funds } \\
k_{j}\end{array}$ & $\begin{array}{c}\text { Fairley } \\
\text { Underwriting } \\
\text { Beta } \\
\beta_{p, j}\end{array}$ \\
\hline Fire & .036 & .7870 & .137 \\
Homeowners & .072 & .7974 & .139 \\
Commercial & .354 & 1.1324 & .197 \\
Auto Liability & .693 & 1.3322 & .232 \\
Auto Physical Damage & .191 & .5229 & .091 \\
\hline
\end{tabular}

Table 2: Underwriting returns by line of insurance given by the proposed model

\begin{tabular}{lccccc}
\hline \multirow{2}{*}{ Insurance Line } & \multicolumn{2}{c}{$\begin{array}{c}\text { Market Value } \\
\text { Capital }\end{array}$} & & \multicolumn{2}{c}{$\begin{array}{c}\text { Statistically } \\
\text { Determined Capital }\end{array}$} \\
\cline { 2 - 3 } & $\begin{array}{c}\text { After } \\
\text { Tax }\end{array}$ & $\begin{array}{c}\text { Differential } \\
\text { Tax }\end{array}$ & & $\begin{array}{c}\text { After } \\
\text { Tax }\end{array}$ & $\begin{array}{c}\text { Differential } \\
\text { Tax }\end{array}$ \\
\hline Fire & -.20 & -.30 & & -.23 & -.35 \\
Homeowners & -.40 & -.60 & & -.46 & -.71 \\
Commercial & -1.95 & -2.95 & & -2.28 & -3.48 \\
Auto Liability & -3.82 & -5.78 & & -4.46 & -6.82 \\
Auto Physical Damage & -1.05 & -1.59 & & -1.23 & -1.88 \\
\hline Weighted Average & -2.05 & -3.10 & & -2.40 & -3.66 \\
\hline
\end{tabular}

Table 3: Underwriting returns by line of insurance required by Fairley's model and historical and traditional target underwriting returns

\begin{tabular}{lccc}
\hline Insurance Line & Fairley Model & $\begin{array}{c}\text { Historical } \\
\text { Margins } \\
1978-82\end{array}$ & $\begin{array}{c}\text { Traditional } \\
\text { Targets }\end{array}$ \\
\hline Fire & -4.96 & 3.76 & 4.0 \\
Homeowners & -5.04 & -2.24 & 6.0 \\
Commercial & -7.68 & -.64 & 4.0 \\
Auto Liability & -9.24 & -8.30 & 5.0 \\
Auto Physical Danage & -2.89 & -.24 & 5.0 \\
\hline Weighted Average & -6.57 & -3.41 & 4.97 \\
\hline
\end{tabular}


tables that underwriting returns given by the tax differential model are closer to the historical returns than those given by the single-tax rate model.

The incorporation of the probability of bankruptcy of the insurance firm, through the statistically determined capital, also tends to increase the potential predictability of the model. In fact, it can be observed in the tables that the underwriting returns given by the versions of the model based on the statistically determined capital reflect the historical returns closer than those given by the versions of the model based on the market value capital.

\subsection{Sensitivity analysis}

Authors such as Myers and Cohn [22], Callaghan and Derrig [6], and Cummins and Harrington [8] have indicated that underwriting betas are not stable across time nor across companies. Myers and Cohn show that the variation of the beta estimates of the liabilities has an impact on the underwriting returns given by the Fairley model. However, their sensitivity analysis exaggerates the instability of the liability beta by allowing large variations of $\beta_{L}$ that go from -.4 to .4 . Callaghan and Derrig present several arguments against the use of betas as a measure of the risk of an insurance firm. They also introduce a table prepared by Wilshire Associates to demonstrate how beta estimates vary according to the method used in computing them. In effect, the table shows that equity betas calculated for the Value Line sample of insurance companies used by Fairley are sensitive to the time period chosen and differ across companies. The same authors point out the problems involved with the different methods of estimating underwriting betas, that is, the strong assumption of a constant liability beta for all lines made by Fairley [10] and the mix of market and accounting returns of the regression approach of Hill [14]. With respect to the latter point, Cummins and Harrington have computed underwriting betas by regressing quarterly rates of underwriting profits, a book value estimate, on quarterly rates of return on alternative market indices. They conclude the choice of market index does not significantly influence the beta estimates, but they are affected by the time period used and the companies considered in the same.

Because of the controversy about underwriting betas, it has been considered interesting to incorporate in this research a sensitivity analysis of the results given by the proposed model to variation in $\beta_{\mu}$. In this respect, confidence level intervals have been computed to reflect the temporal and sectional variability of the underwriting betas. The across time instability of $\beta_{\mu}$ has been captured by computing the sample mean and variance of $\beta_{\mu}$, for the time period 1975-1979, and then constructing a 95-percent confidence level interval. The underwriting returns corresponding to the lower and upper bounds of the 95-percent confidence level of $\beta_{\mu}$ for each insurance line and for each of the different versions of the proposed model are presented in Table 4 and 5.

From Tables 4 and 5, we can see that a 95-percent confidence level interval for temporal variation of $\beta_{\mu}$ gives underwriting returns for line of insurance that do not deviate, in general, more than 10-percent from the average values given in Table 2 . That is, the instability of underwriting beta over time does not seem to have a significant impact on the underwriting returns. ${ }^{9}$

\footnotetext{
${ }^{9}$ The impact of the temporal variability of the underwriting betas on the underwriting returns has also been analyzed by generating a distribution for the underwriting returns. In generating this distribution, the only parameter that was allowed to vary was the underwriting beta. The null hypothesis $\operatorname{var}\left(\mu_{j}\right)=0$ could not be rejected at the 10 -percent level.
} 
Table 4: Underwriting returns for line insurance with a 95-percent confidence level interval for temporal variation of $\beta_{\mu}$ and market value capital

\begin{tabular}{lccccc}
\hline Insurance Line & \multicolumn{2}{c}{ After Tax } & & \multicolumn{2}{c}{ Differential Tax } \\
\cline { 2 - 3 } & $\begin{array}{l}\text { Lower } \\
\text { Bound }\end{array}$ & $\begin{array}{l}\text { Upper } \\
\text { Bound }\end{array}$ & & $\begin{array}{l}\text { Lower } \\
\text { Bound }\end{array}$ & $\begin{array}{c}\text { Upper } \\
\text { Bound }\end{array}$ \\
\hline Fire & -.22 & -.18 & & -.32 & -.28 \\
Homeowners & -.44 & -.35 & & -.64 & -.55 \\
Commercial & -2.14 & -1.73 & & -3.14 & -2.73 \\
Auto Liability & -4.19 & -3.38 & & -6.15 & -5.34 \\
Auto Physical Damage & -1.16 & -.93 & & -1.70 & -1.47 \\
\hline
\end{tabular}

Table 5: Underwriting returns for line of insurance with a 95-percent confidence level interval for temporal variation of $\beta_{\mu}$ and statistically determined capital

\begin{tabular}{lccccc}
\hline \multirow{2}{*}{ Insurance Line } & \multicolumn{2}{c}{ After Tax } & & \multicolumn{2}{c}{ Differential Tax } \\
\cline { 2 - 3 } & $\begin{array}{l}\text { Lower } \\
\text { Bound }\end{array}$ & $\begin{array}{l}\text { Upper } \\
\text { Bound }\end{array}$ & & $\begin{array}{l}\text { Lower } \\
\text { Bound }\end{array}$ & $\begin{array}{c}\text { Upper } \\
\text { Bound }\end{array}$ \\
\hline Fire & -.25 & -.21 & & -.37 & -.33 \\
Homeowners & -.50 & -.42 & & -.75 & -.66 \\
Commercial & -2.47 & -2.06 & & -3.68 & -3.26 \\
Auto Liability & -4.84 & -4.02 & & -7.20 & -6.38 \\
Auto PhysicalDamage & -1.33 & -1.11 & & -1.98 & -1.76 \\
\hline
\end{tabular}

Other interesting results given by Table 4 and 5 are the following: First, the range of values of the underwriting returns for each insurance line for the single-tax case and the taxdifferential case do not overlap each other. this means that the underwriting returns obtained from these versions of the proposed model are statistically significantly different. This important result suggests that a different tax treatment for underwriting profit and investment income is quite appropriate in the determination of fair underwriting returns by line of insurance. Secondly, the interval or range of values for the underwriting returns for each line of insurance given by the versions of the model based on the market value capital and the statistically determined capital practically do not overlap each other either. In other words, the underwriting returns given by the proposed model when the probability of bankruptcy of the insurer is incorporated into it are different in a statistical sense from those given by the model 
based on the market value capital. This allows us to conclude that the probability of bankruptcy is another relevant factor to be considered in the determination of fair underwriting returns for each line of insurance. ${ }^{10}$

The across-company variation of $\beta_{\mu}$ has been analyzed by changing the size of the sample. In this respect, a 95-percent confidence level interval for underwriting beta for a larger sample of stock insurance companies has been computed. The corresponding underwriting returns given by the different versions of the proposed model are presented in Tables 6 and 7 .

It is interesting to compare the results of Tables 6 and 7 with those already presented in Tables 4 and 5. It is clear that the range of values of underwriting returns, in Tables 4 and 5 and those presented in Tables 6 and 7 overlap each other along almost the whole range of values. This is true for both the market value capital and the statistically determined capital models. The relevant conclusion here is that the variation of underwriting beta due to the sample size seems to have no statistically significant effect on the determination of underwriting returns for each line of insurance."

\section{Summary and conclusions}

This paper develops a model for the determination of underwriting returns for the individual insurance lines of a multi-line property-liability insurer. The proposed model is intended to contribue to clarifying the controversial issue of insurance price regulation in the United States. In fact, rate regulation in insurance is not based on definitive standards and varies from state to state. Even though some states have ruled out taking investment income into account in the ratemaking process, they have failed to specify pricing formulas compatible with economic and financial theories. In this respect, the model proposed in this paper is based on the Capital Asset Pricing Model and the Portfolio Theory, two main developments in the modern financial theory of capital markets. Underwriting return formulas are derived for the beforetax, after-tax, and tax-differential cases. The suggested model attempts to correct the main shortcomings of the Fairley model, which has been subjected to intense criticism in recent years. The main differences between the financial model derived in this paper and the Fairley model are the following: i) the proposed model drops Fairley's assumption of an all-lines constant liabilities beta. Instead, underwriting returns by individual insurance lines are

${ }^{10}$ The effects of different corporate tax rates for underwriting profit and investment income and the probability of bankruptcy of the insurance firm have also been studied by generating probability distributions for the underwriting returns and conducting statistical tests of difference of means. The following null hypotheses have been tested:

1) Mean underwriting return of the single-tax model= mean underwriting return of the tax-differential model.

2) Mean underwriting return of the market value capital model = mean underwriting return of the statistically determined capital model.

Both null hypotheses were rejected at the 10 -percent level.

"Tests of the difference of means were also conducted in order to test the statistically significant difference of the average underwriting returns given by the different versions of the model of Tables 6 and 7 and those given in Tables 4 and 5 . See footnote 10.) The null hypothesis of equal means could not be rejected at the 10 -percent level. 
Table 6: Underwriting returns for line of insurance with a 95-percent confidence level interval for sectional variation of $\beta_{\mu}$ and market value capital

\begin{tabular}{lccccc}
\hline \multirow{2}{*}{ Insurance Line } & \multicolumn{2}{c}{ After Tax } & & \multicolumn{2}{c}{ Differential Tax } \\
\cline { 2 - 3 } \cline { 5 - 6 } & Lower & Upper & & Lower & Upper \\
& Bound & Bound & & Bound & Bound \\
\hline Fire & -.24 & -.18 & & -.35 & -.30 \\
Homeowners & -.48 & -.36 & & -.71 & -.59 \\
Commercial & -2.35 & -1.77 & & -3.48 & -2.90 \\
Auto Liability & -4.59 & -3.47 & & -6.81 & -5.68 \\
Auto Physical Damage & -1.27 & -.96 & & -1.88 & -1.57 \\
\hline
\end{tabular}

Table 7: Underwriting returns for line of insurance with a 95-percent confidence level interval for sectional variation of $\beta_{\mu}$ and statistically determined capital

\begin{tabular}{lccccc}
\hline \multirow{2}{*}{ Insurance Line } & \multicolumn{2}{c}{ After Tax } & & \multicolumn{2}{c}{ Differential Tax } \\
\cline { 2 - 3 } \cline { 5 - 6 } & $\begin{array}{l}\text { Lower } \\
\text { Bound }\end{array}$ & $\begin{array}{c}\text { Upper } \\
\text { Bound }\end{array}$ & & $\begin{array}{l}\text { Lower } \\
\text { Bound }\end{array}$ & $\begin{array}{c}\text { Upper } \\
\text { Bound }\end{array}$ \\
\hline Fire & -.27 & -.21 & & -.40 & -.34 \\
Homeowners & -.54 & -.42 & & -.80 & -.69 \\
Commercial & -2.63 & -2.06 & & -3.92 & -3.38 \\
Auto Liability & -5.16 & -4.04 & & -7.67 & -6.62 \\
Auto Physical Damage & -1.42 & -1.11 & & -2.11 & -1.82 \\
\hline
\end{tabular}

directly derived from the total underwriting return of insurance portfolio by means of the risk proportional method, ii) the suggested model also gives a more realistic treatment to the taxation problem by incorporating different tax rates for underwriting profit and investment income, iii) the proposed model also recognizes the probability of insolvency of the insurer by means of the statistically determined capital and iv) the empirical tests of the proposed model incorporate also a sensitivity analysis of the underwriting returns to variation of underwriting betas. Results of the empirical tests allow us to conclude the following:

- The underwriting returns by line of insurance given by the proposed model are negative. These results agree with those reported by Fairley and suggest that insurance companies make their profits mainly in their investment operations.

- The underwriting returns by line of insurance given by the different versions of the proposed model represent the data better than the Fairley model.

- The incorporation of different corporate tax rates for the investment income and the underwriting profit increase the predictability of the proposed model.

- The incorporation of the probability of bankruptcy of the insurance firm, through the statistically determined capital, also contributes to improving the predictability of the proposed model. 
Sensitivity analysis of the results given by the proposed model indicates that the temporal and sectional variability of underwriting beta has no significant impact on the underwriting returns. The sensitivity analysis also establishes that different tax rates for investment income and underwriting profit and the probability of bankruptcy of the insurance firm are relevant factors and should be taken into account in the property-liability insurance ratemaking process.

The model developed and empirically tested in this study is consistent with modern financial theory. It represents an effort to extend and improve previous models, which have been subject to criticism from the insurance industry. Indeed, the pricing formulas derived in this paper are considered appropriate for implementation by regulatory authorities. In fact, the competitive underwriting returns given by the proposed model represent a reference framework against which the objectives of the regulation of property-liability insurance prices can be evaluated.

\section{REFERENCES}

1. A. M. BEST COMPANY: Best's Aggregates and Averages, Property-Liability Edition (New Jersey).

2. A. M. BEST COMPANY: Best's Insurance Reports, Property-Liability Edition (New Jersey).

3. BIGER, N., and Y. KAHANE: "Risk considerations in insurance ratemaking", Journal of Risk and Insurance, 45 (March 1978), 121-132.

4. BLACK, F., JENSEN, M. C., and SCHOLES, M.: "The capital asset pricing model: Some empirical tests", in Jensen (ed.), Studies in the Theory of Capital Markets (New York: Praeger, 1972).

5. BUTSIC, R. P.: "Risk and return for property-casualty insurers", Total Return Due a Property and Casualty Company, 1979 Call Paper Program, May 20-23, Casualty Actuarial Society, pp. 52-83.

6. CALLAGHAN, A. H., and DERRIG, A.: "Position paper on the risk and reward for underwriting", Report prepared for the Insurance Bureau of Massachusetts, June 1982.

7. COOPER, W.: Investment Return and Property-Liability Insurance Ratemaking (Homewood, Ill.: Richard D. Irwin, Inc., June 1974).

8. CUMMINS, J. D., and HARRINGTON, E.: "Property-liability insurance rate regulation: Estimation of underwriting betas using quarterly data", Journal of Risk and Insurance, 52 (1984), 16-43.

9. CUMMINS, J. D., and NYE, D. J.: "Portfolio optimization models for property-liability insurance companies: An analysis and some extensions", Management Science, 27 (April 1981), 414-430.

10. FAIRLEY, W. B.: "Investment income and profit margins in property-liability insurance: Theory and empirical results". Bell Journal of Economics, 10 (Spring 1979), 192-210.

11. FAMA, E., and MACBETH, J.: "Risk, return and equilibrium: Empirical tests", Jourmal of Political Economy, 71 (May/June 1973), 607-636.

12. FERRARI, J.: “A theoretical portfolio selection approach for insuring property and liability lines", Proceeding of the Casualty Actuarial Society, 54 (May 1967), 33-69. 
13. HAUGEN, R. A., and KRONCKE, C. O.: "A portfolio approach to optimizing the structure of capital claims and assets of a stock insurance company", Journal of Risk and Insurance, 37 (March 1970), 41-49.

14. HILL, R. D.: "Profit regulation in property-liability insurance", BellJournal of Economics, 10 (Spring 1979), 172-191.

15. HOFFLANDER, E., and DUVALL, R. M.: "The ruin problem in multiple line insurance: A simplified model", Journal of Financial and Quantitative Analysis, 2 (June 1967), 150-165.

16. IBBOTSON, R. C., and SINQUEFIELD, R. A.: Stock, Bonds, Bills, and Inflation: Historical Returns (1926-1980), 2nd Edition (Charlottesville, VA: Financial Analysis Research Foundation, 1982).

17. KAHANE, Y, and NYE, D.: "A portfolio approach to the property-liability insurance industry", Journal of Risk and Insurance, 42, (December 1975), 579-598.

18. KAHANE,Y.: "The theory of insurance risk premiums: A reexamination in light of recent developments in capital market theory", ASTIN Bulletin, 10 (1979), 223-239.

19. KROUSE, C. G.: "Portfolio balancing corporate assets and liabilities with special attention to insurance management", Journal of Financial and Quantitative Analysis, 5 (March 1970), 77-105.

20. LAMBERT, E. W., and HOFFLANDER, A. E.: "Impact of new multiple line underwriting on investment portfolios of property-liability insurers", Journal of Risk and Insurance, 33 (June 1966), 209-223.

21. LINTNER, J.: "Security prices, risk, and maximal gains from diversification", Journal of Finance, 20 (December 1965), 587-615.

22. MYERS, S. C., and COHN, R. A.: "Insurance rate of return, regulation and the capital asset pricing model", report prepared for the Insurance Bureau of Massachusetts, October 1981.

23. QUIRIN, G. D., and WATERS, W. R.: "Market efficiency and the cost of capital: The strange case of fire and casualty insurance companies", Journal of Finance, 30 (May 1975), 427-450.

24. STANDARD AND POOR'S CORPORATION: Security Price Index Record (New York).

25. VALUE LINE, INC.: Value Line Investment Service, Edition 4 (New York).

26. WEBB, B. L.: "Investment income in insurance ratemaking", Journal of Insurance Regulation, 1 (September 1982), 46-76. 